\title{
Visual Intelligence and the Terminator
}




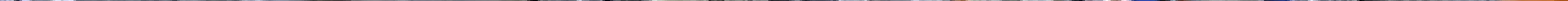


https://www.youtube.com/watch?v=gy5g33S0Gzo 


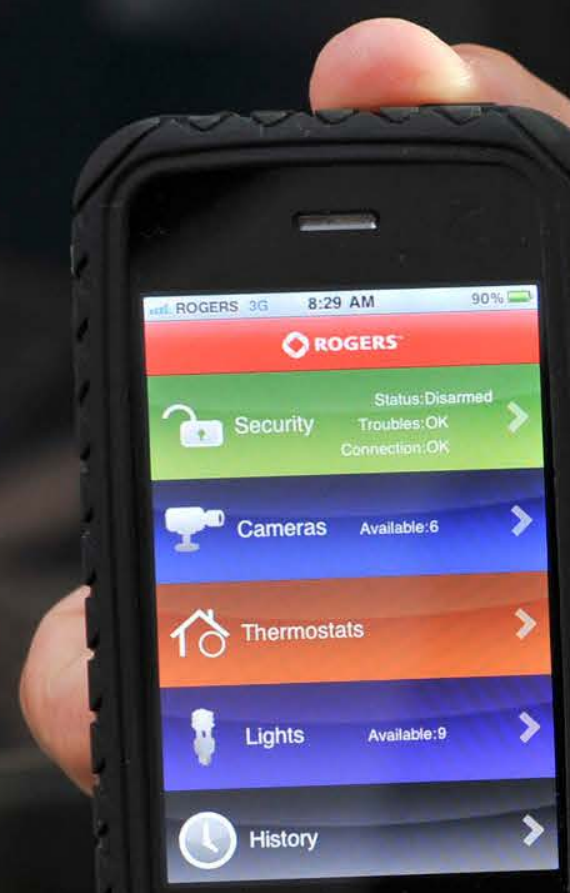

○

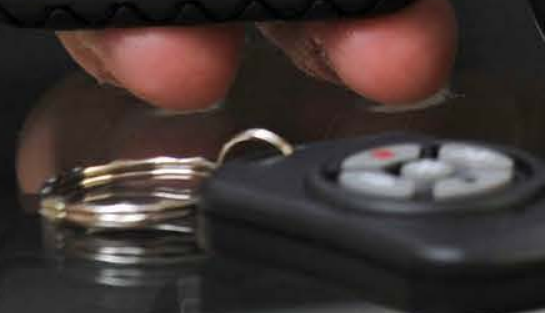

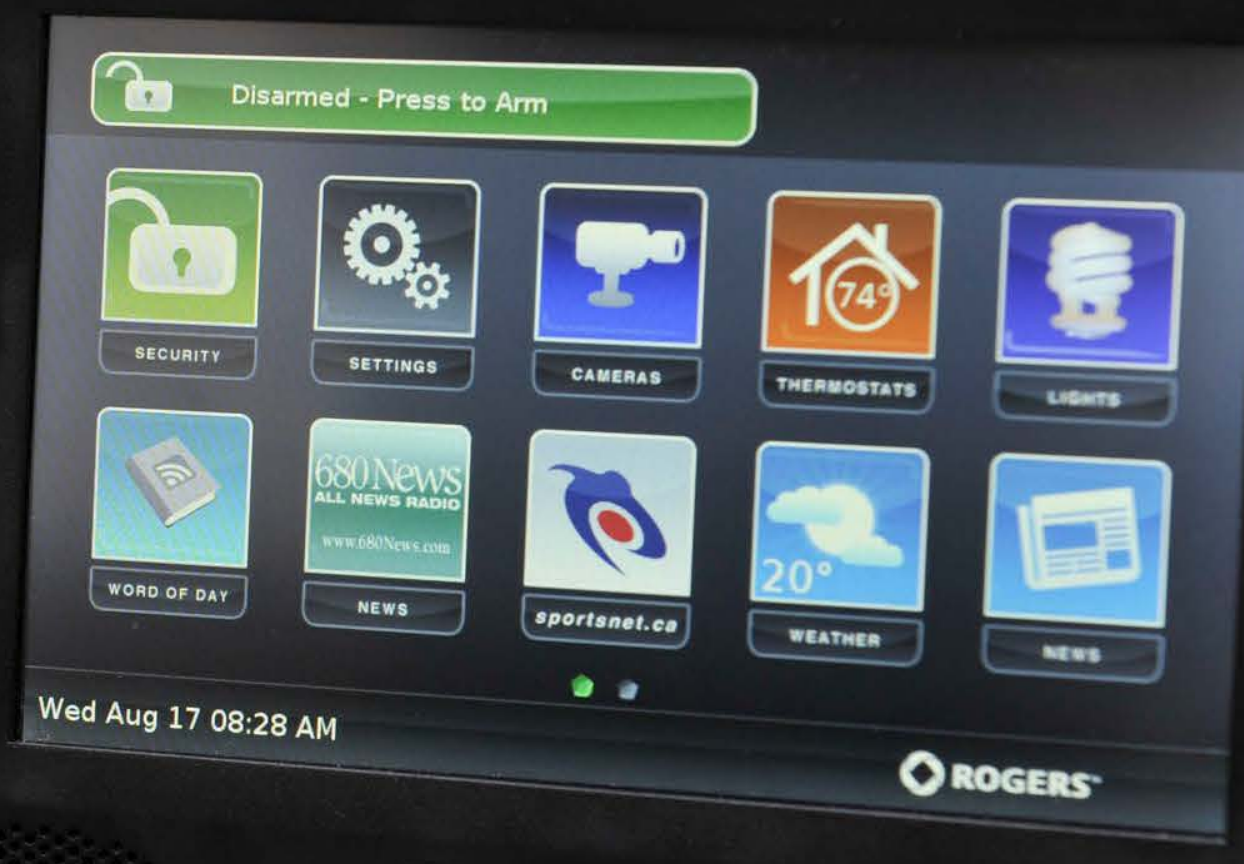

( $) \quad 0$

\& 8




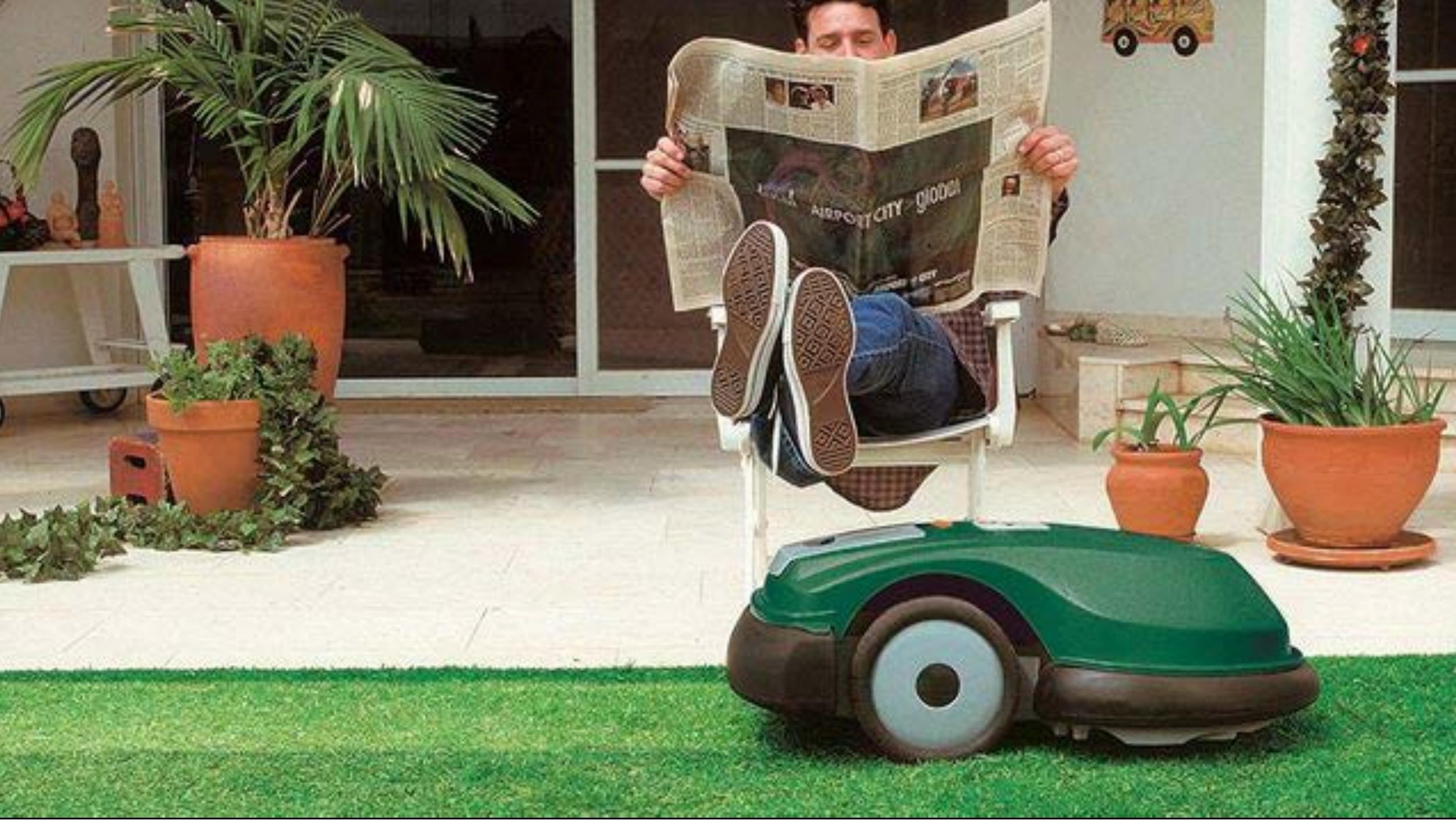




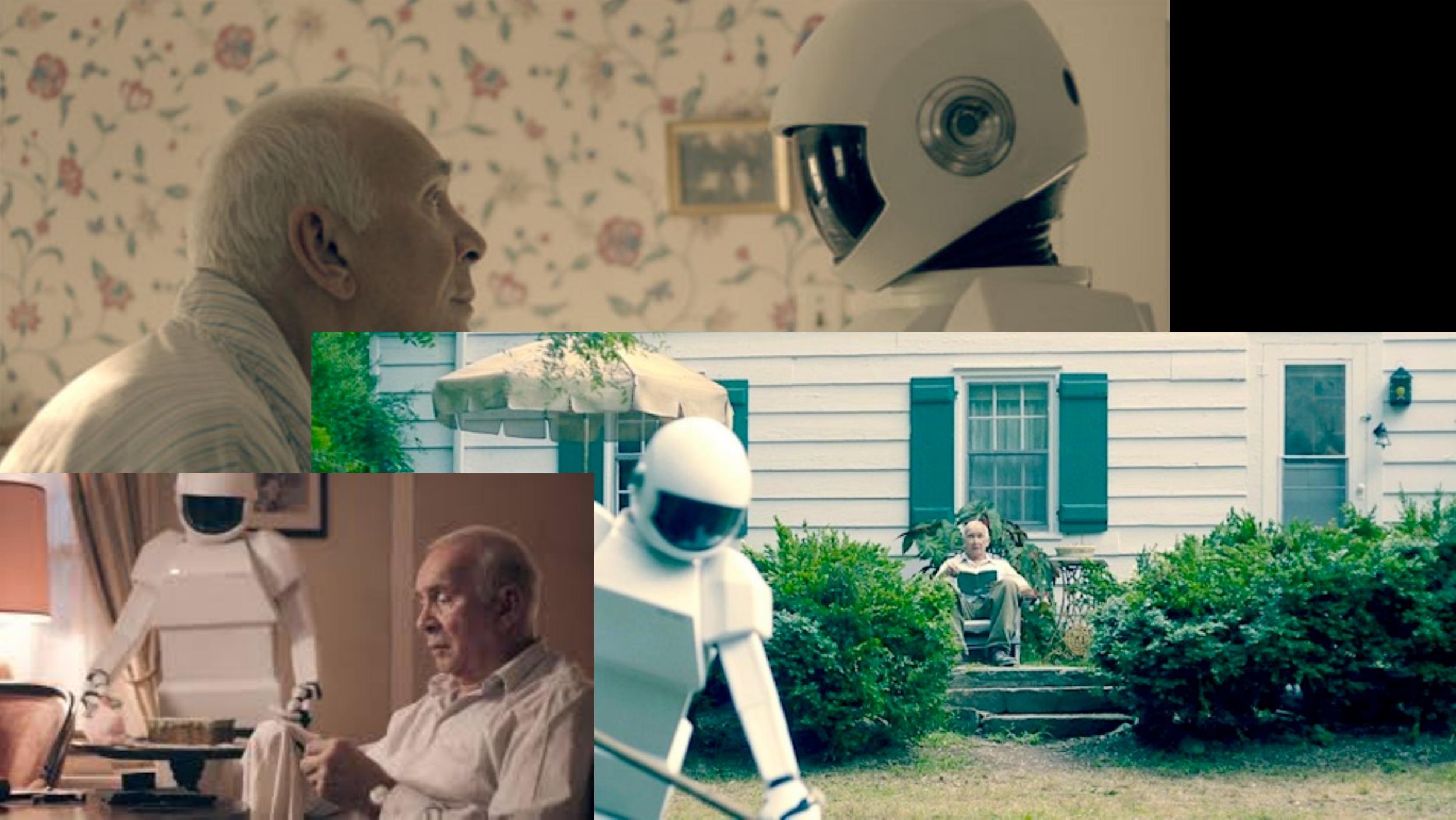




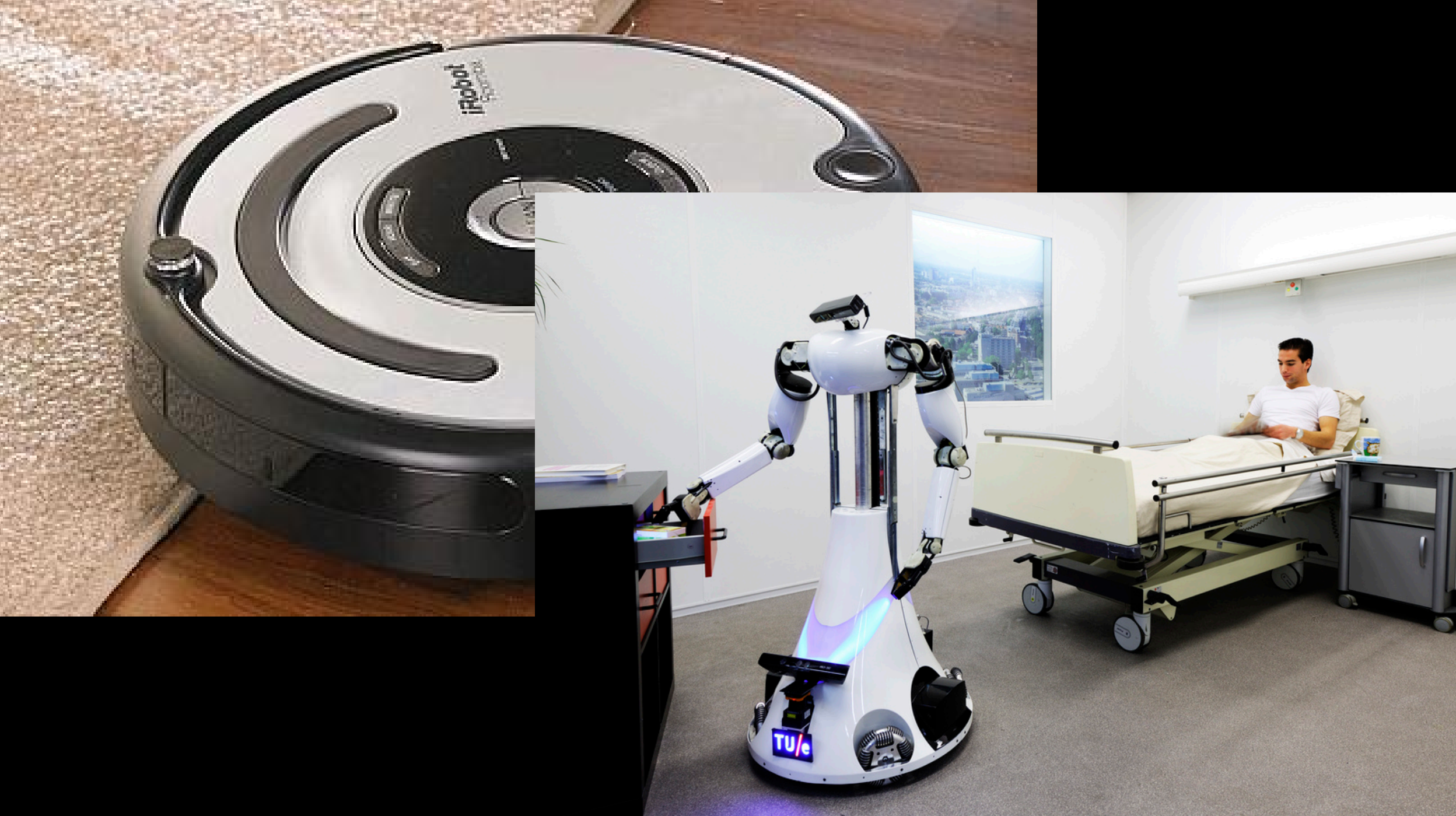




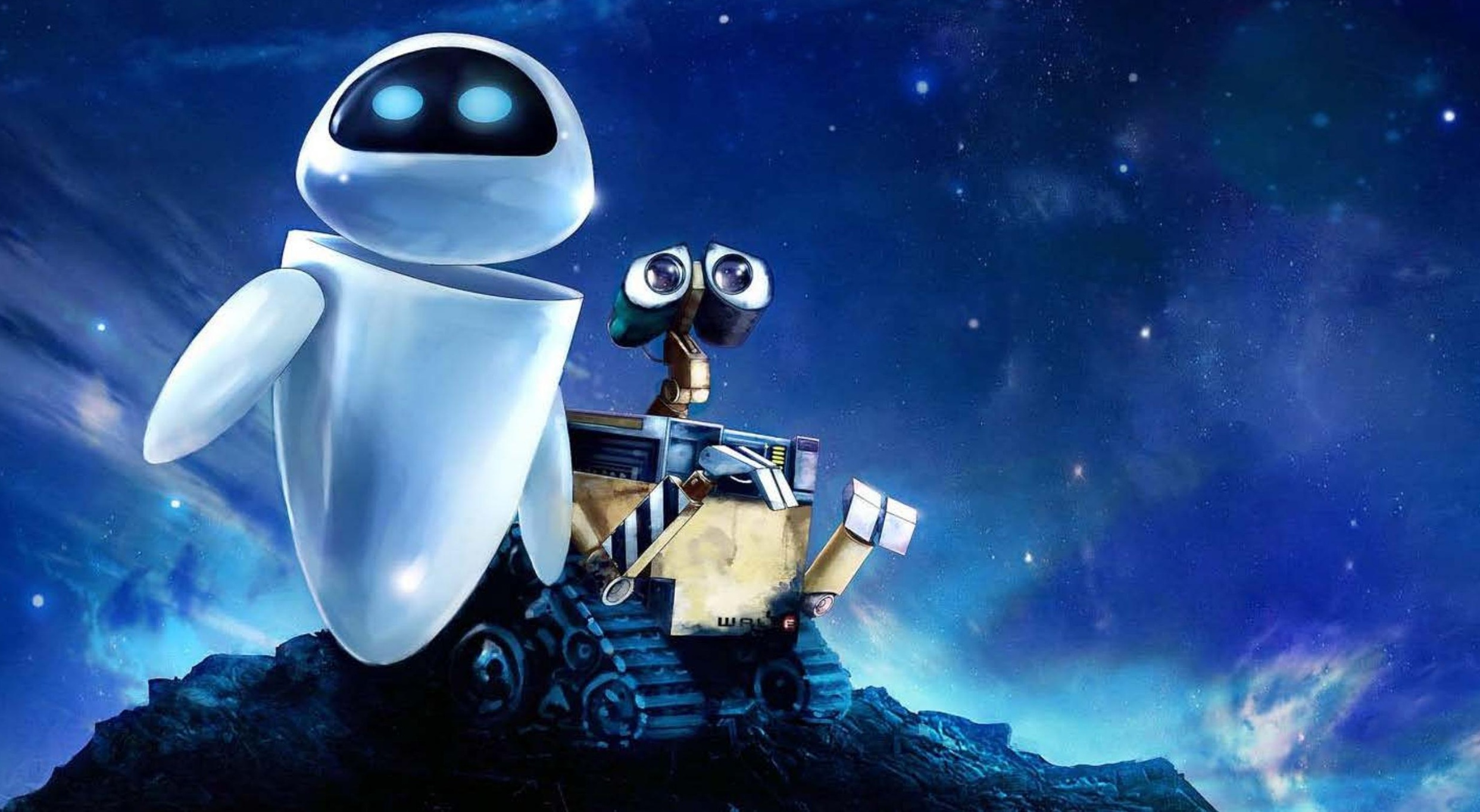




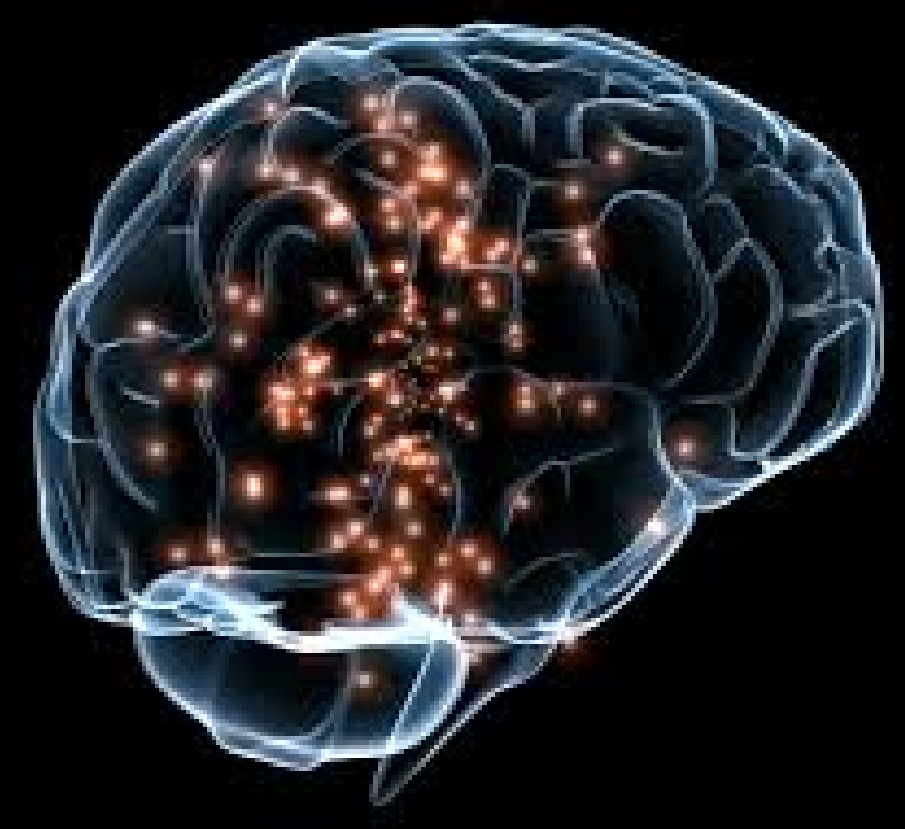

int man ()

int min, akt

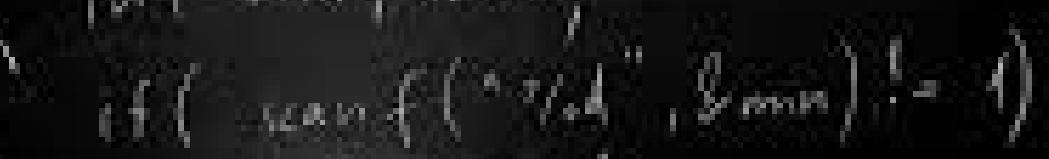

$r+\tan n=1$

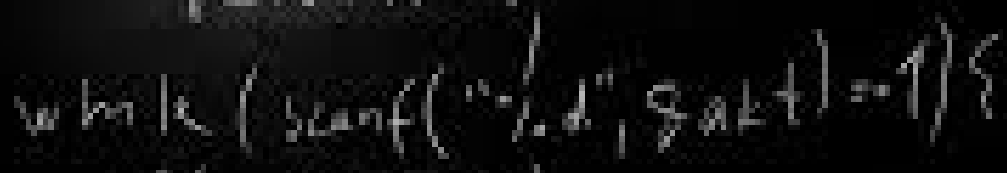

$4(4) 4<$ wh $)$

Hing $=14$

pind $\left(x_{H} / w_{n}\right)$

1 


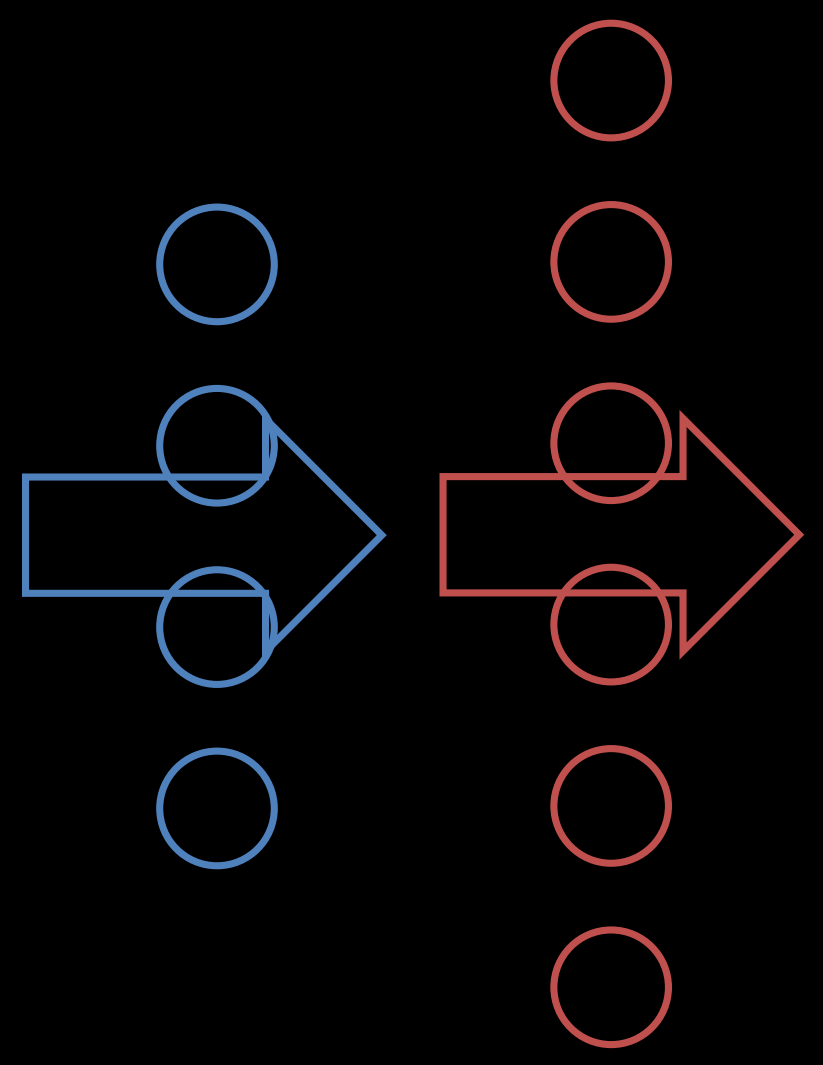

0

0

0

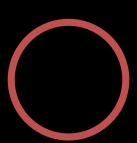

0

0

0

0

0

0

0

○

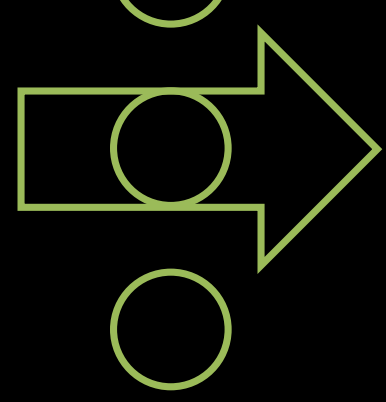

O

0

0 


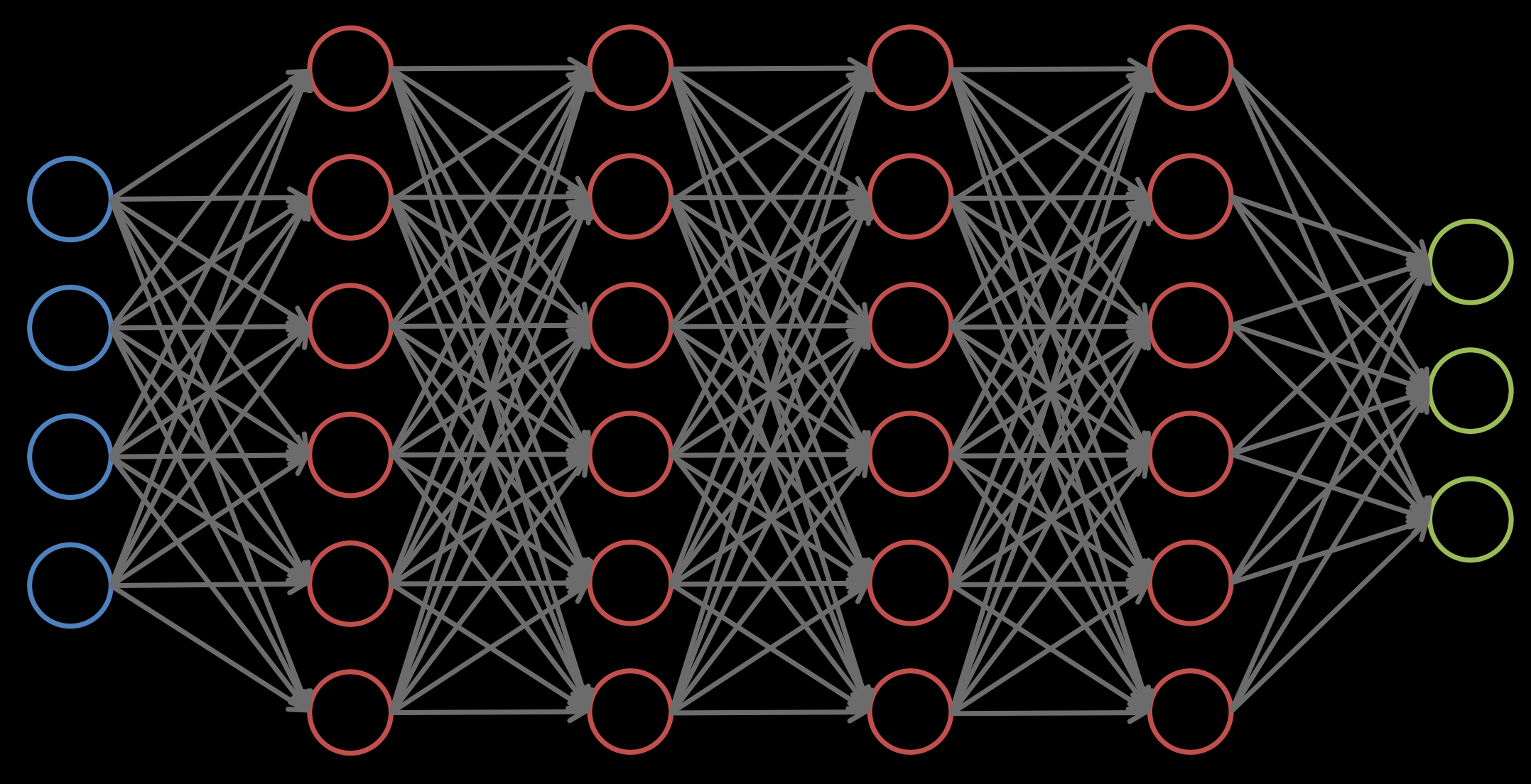




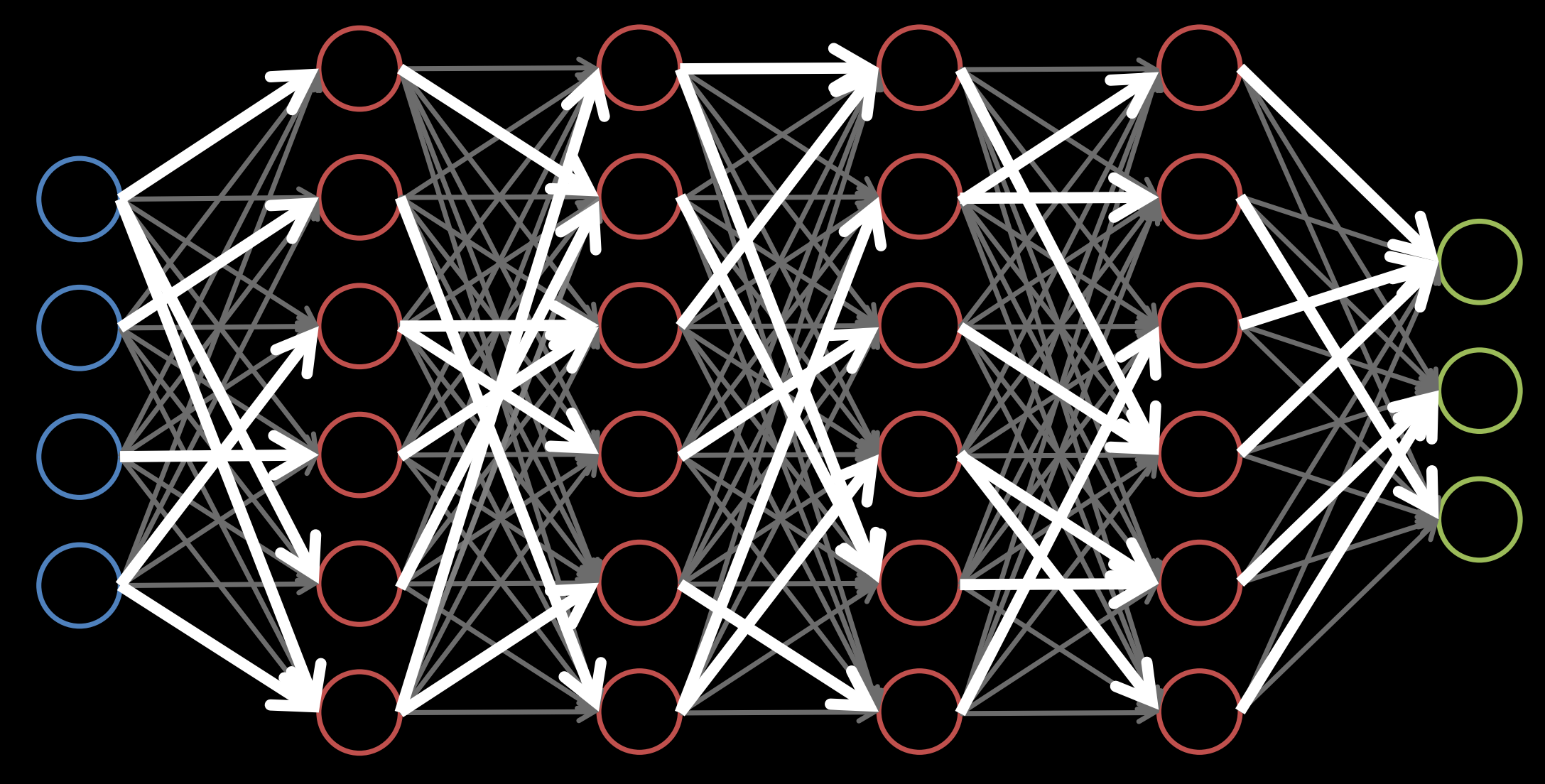




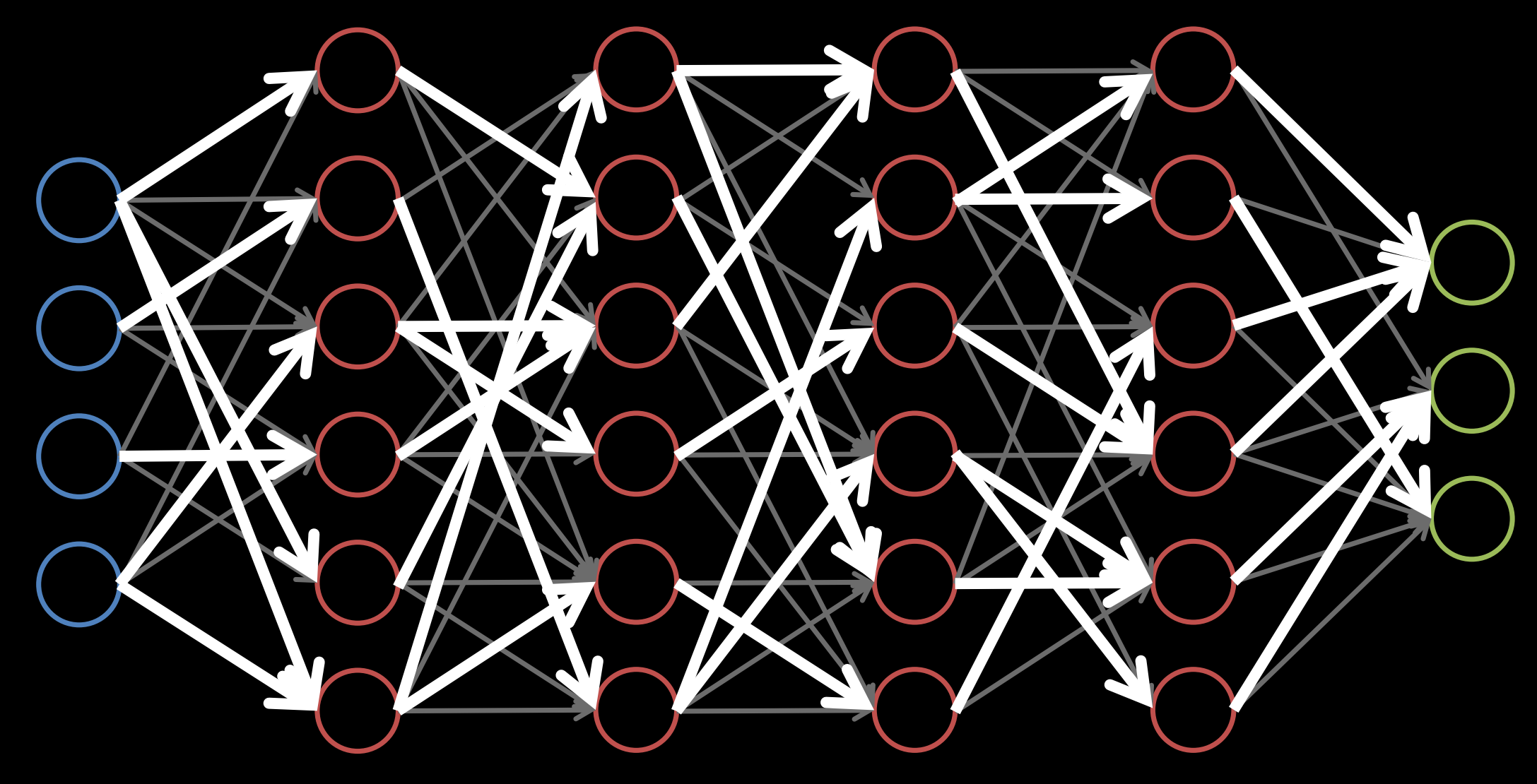




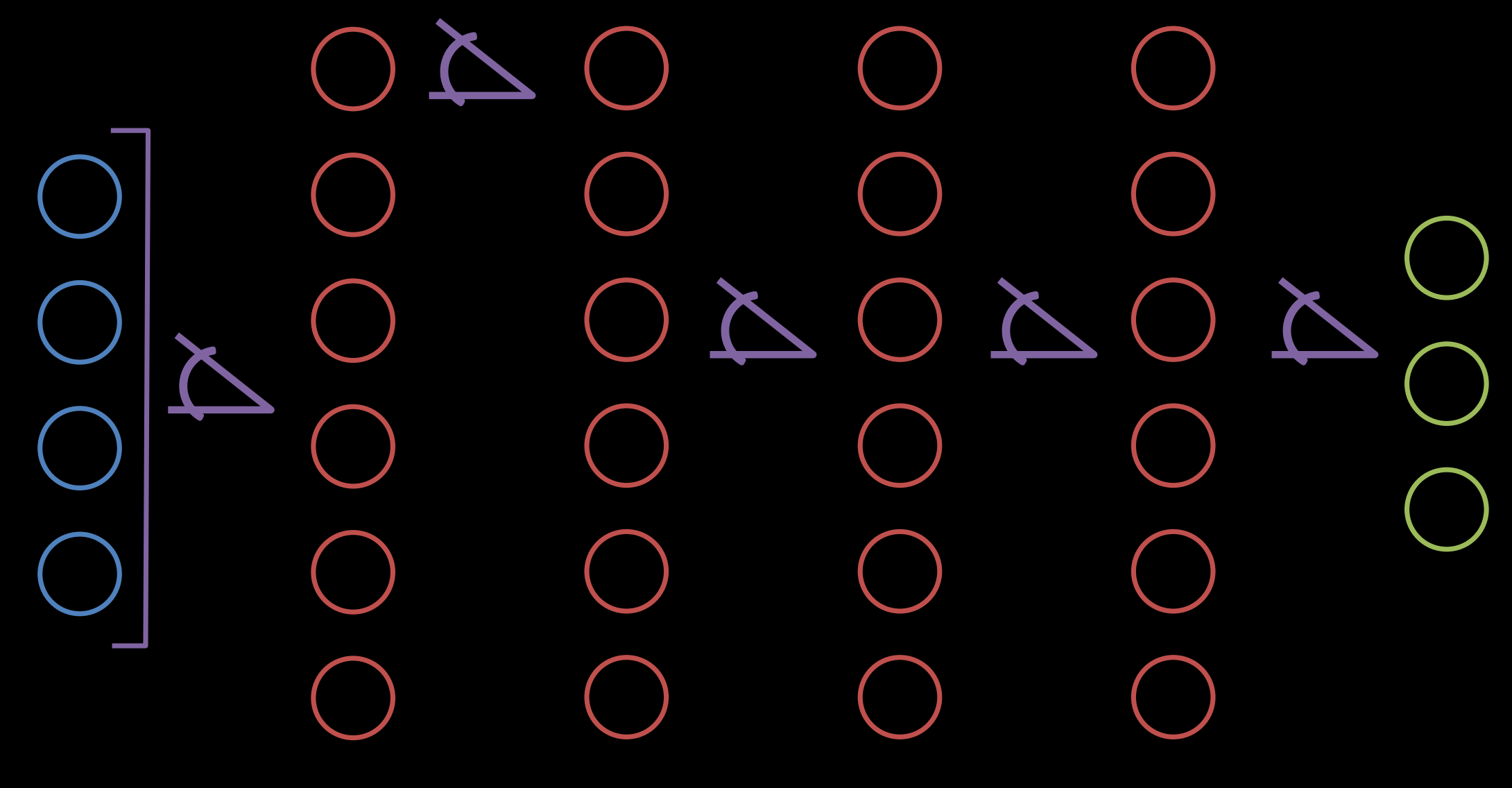


https://www.youtube.com/watch?v=XVlh6zOM_RY 


\section{Google}

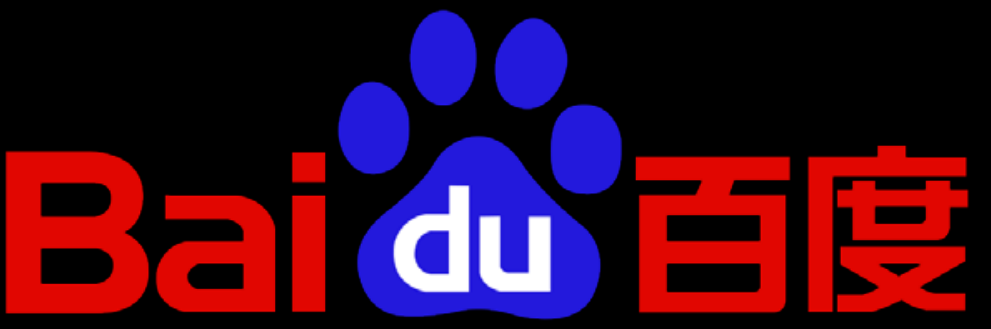

facebook. 


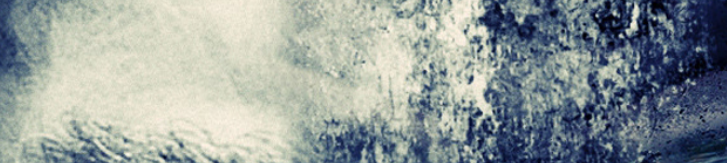

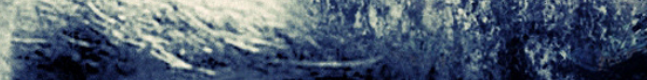

(…)

(ereysing
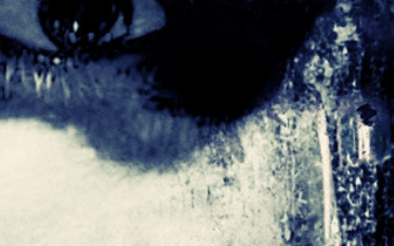

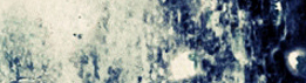

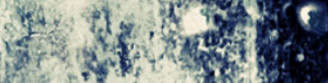

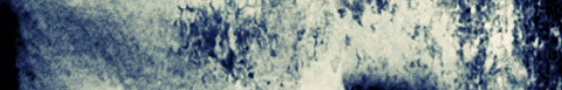

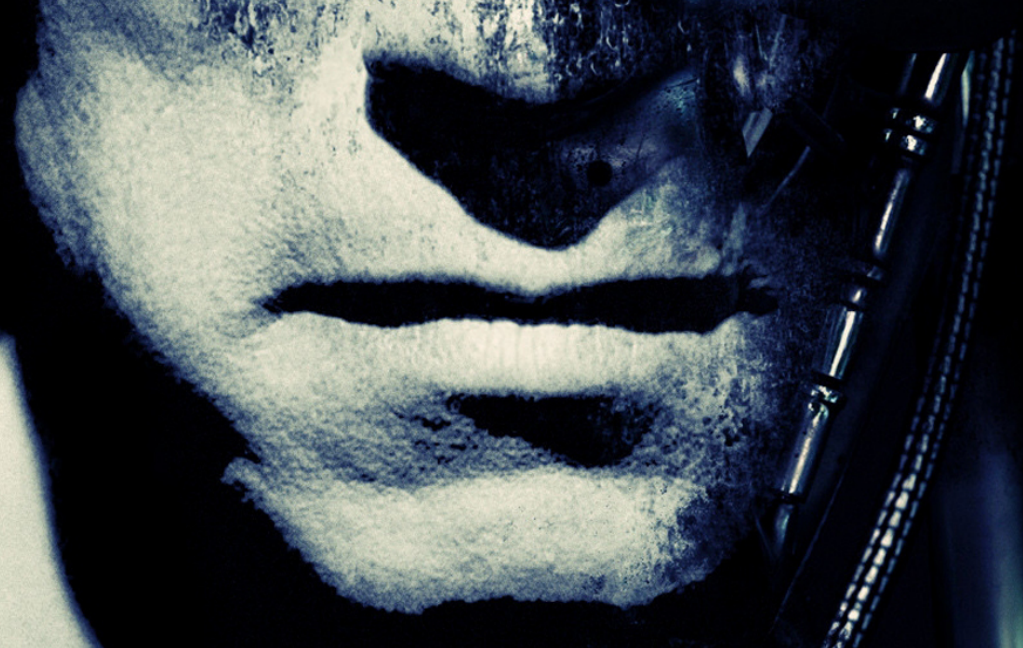

$4 x=-\cdots=-\cdots$

sis. -5
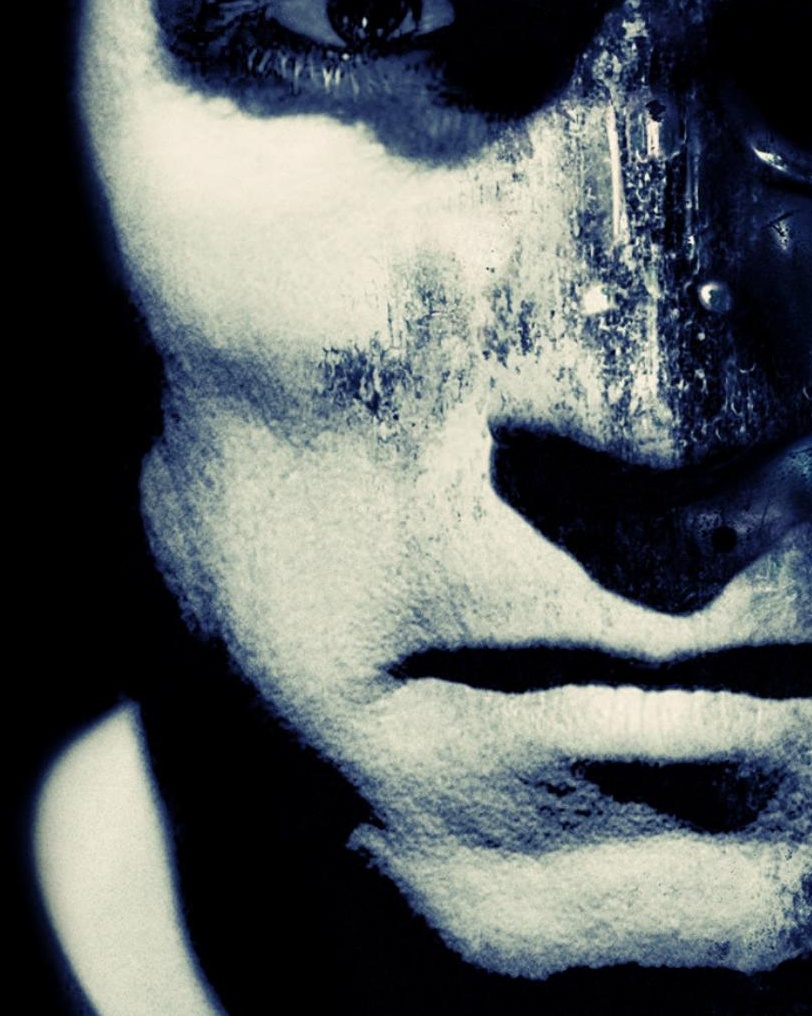

$\because$,

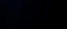


4.

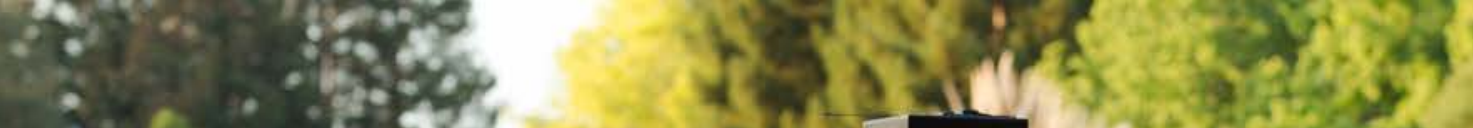

age: . 3

is 3

graves

20.

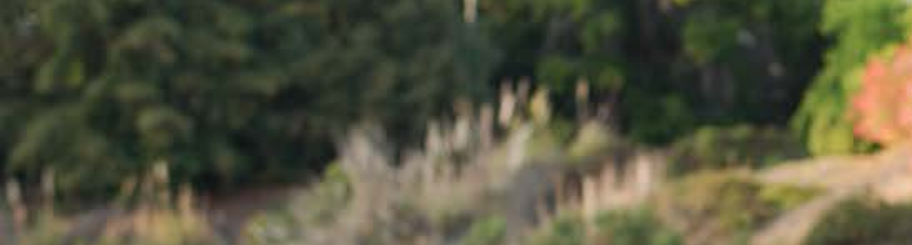

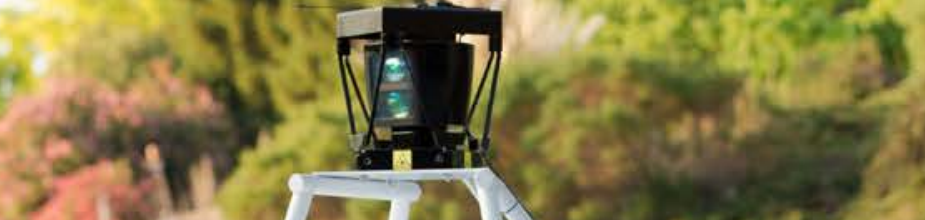

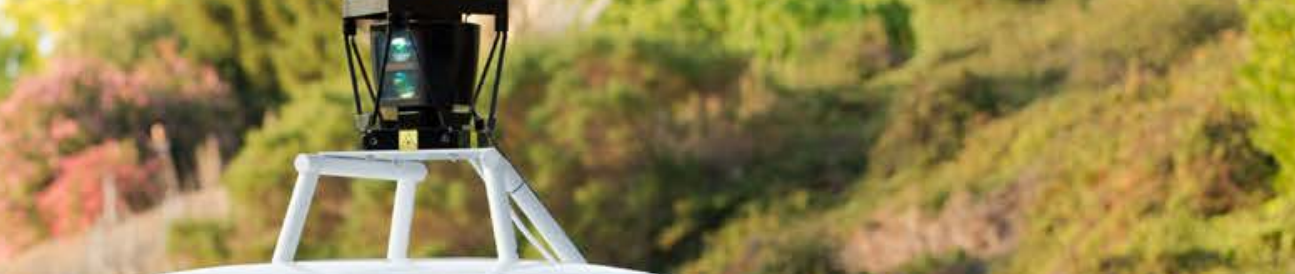

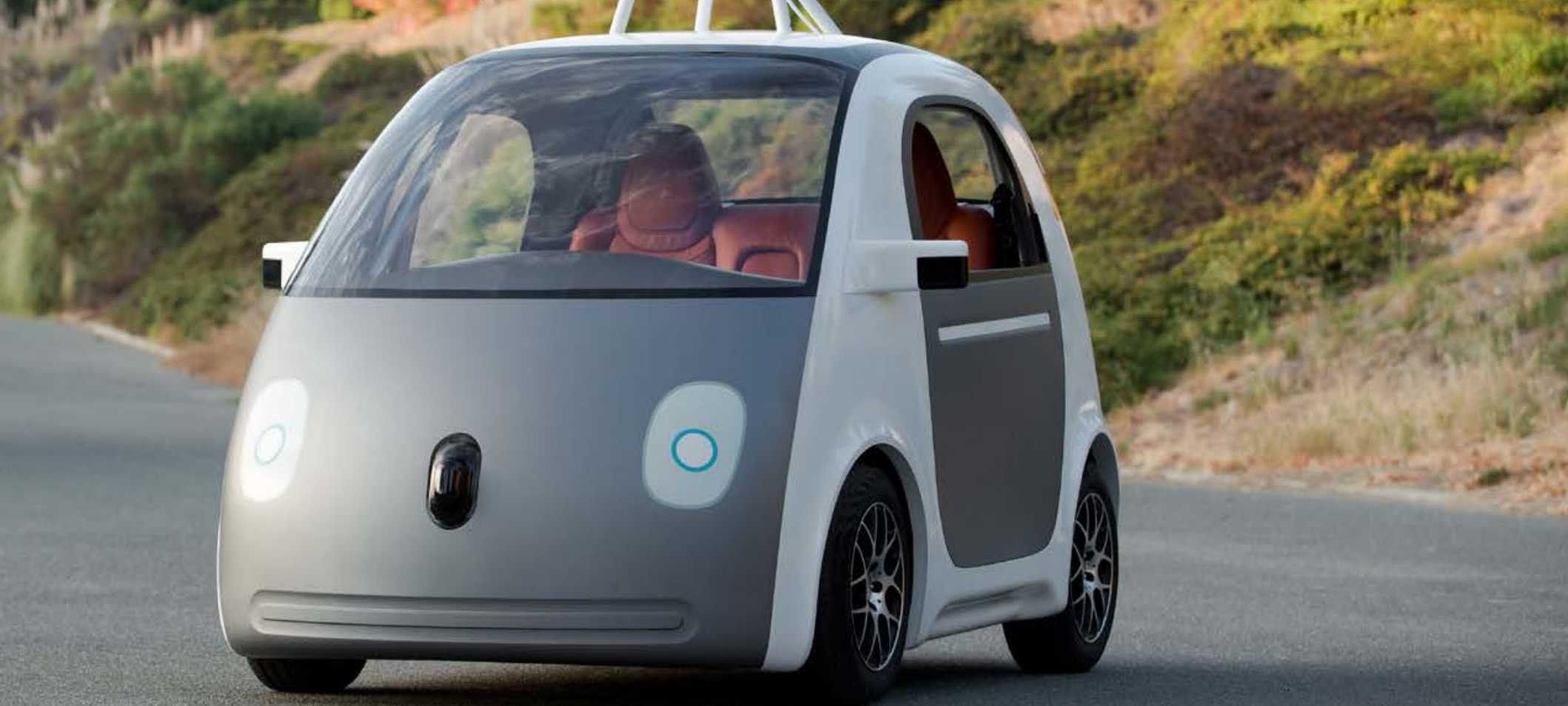




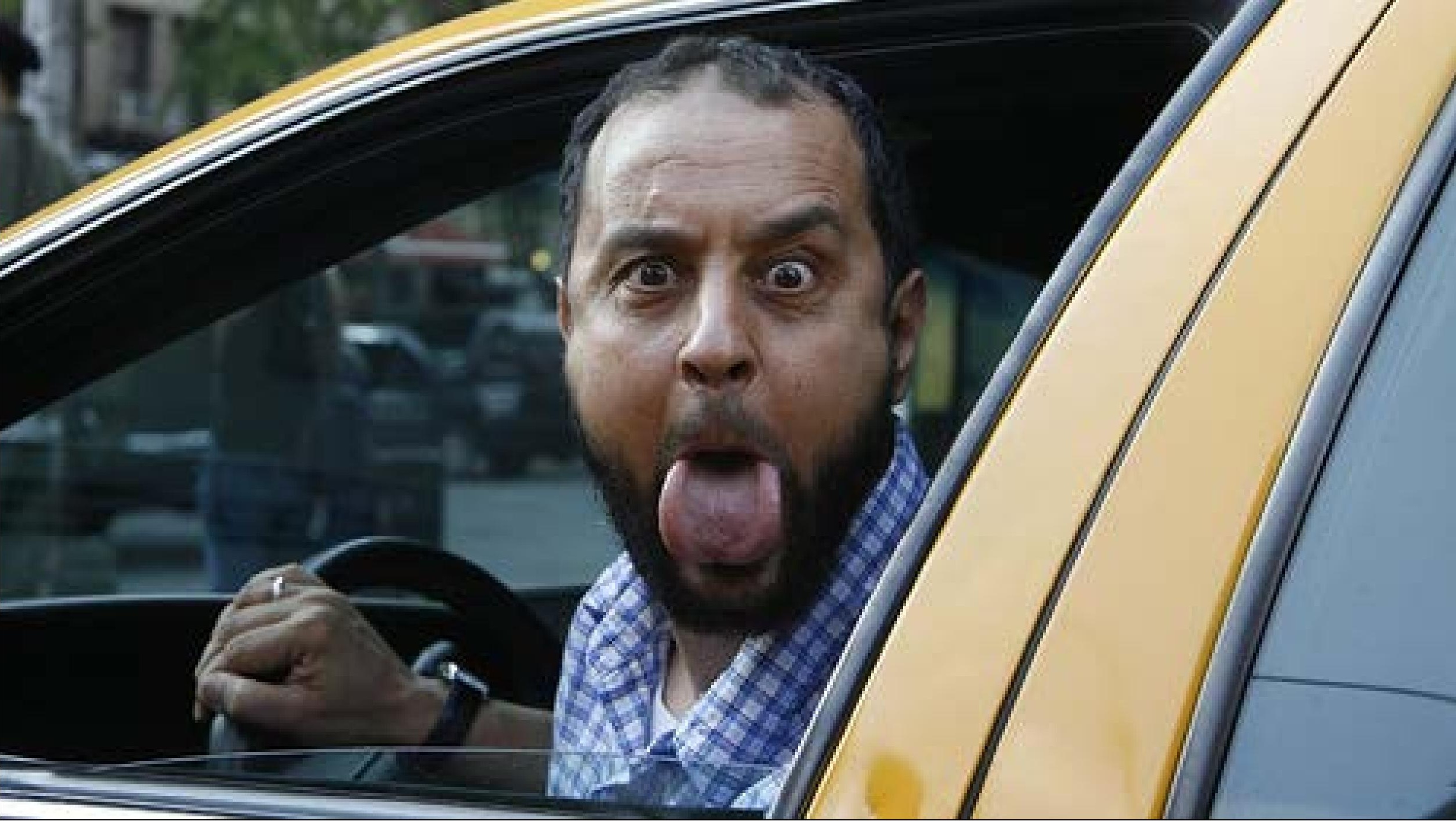




\section{Car crash fatalities}

50,000

40,000

30,000

20,000

10,000

0
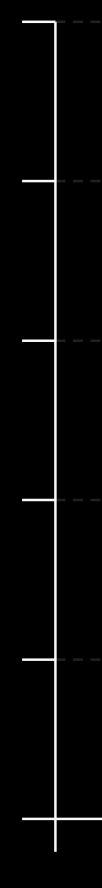

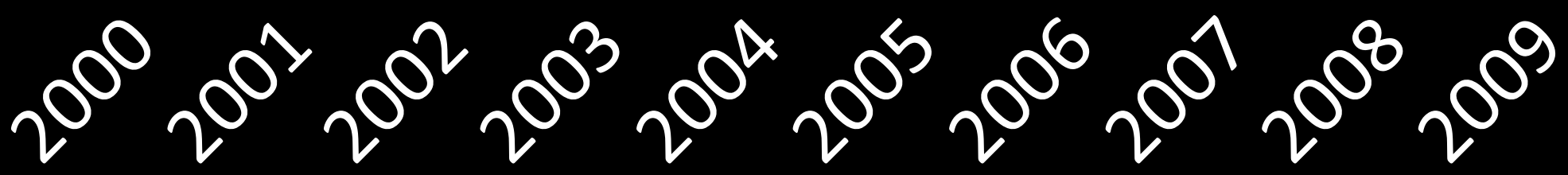




\section{$\frac{\text { PURDUE }}{\text { U NIVERIT }}$}

e-Lab

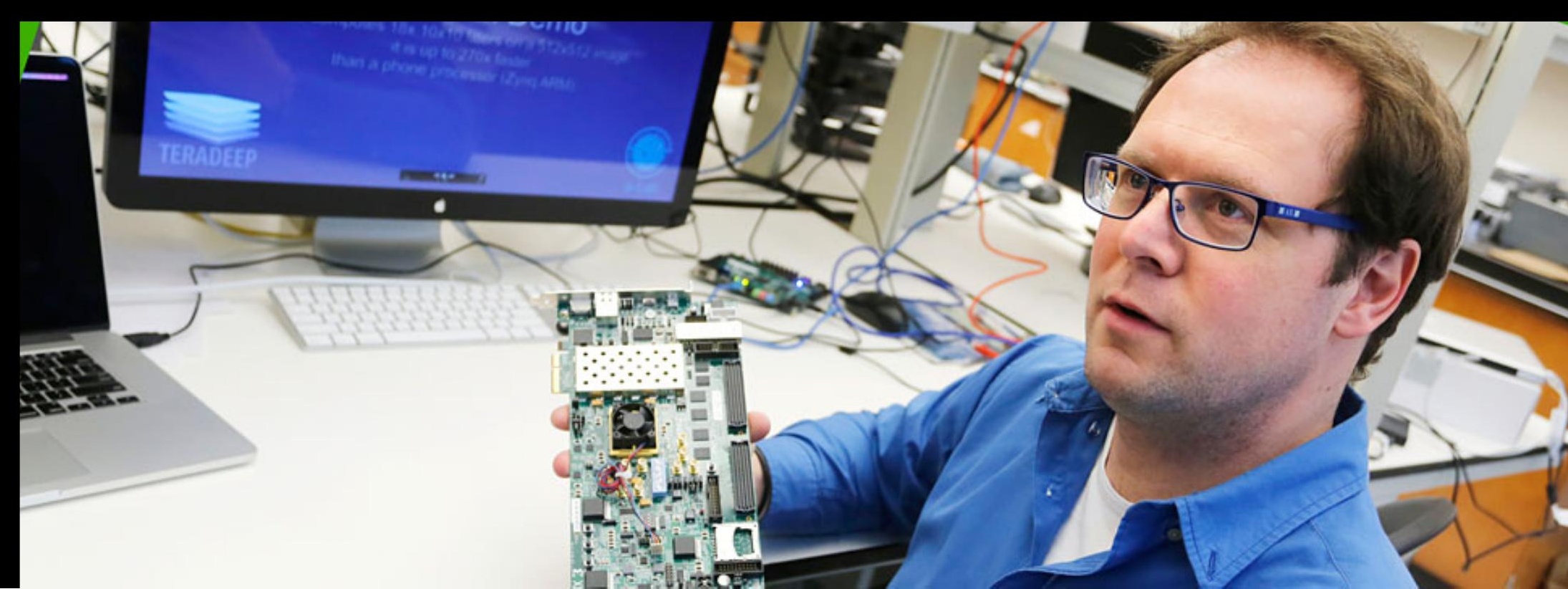

